\title{
Alternative products against anthracnose affect selected primary and secondary metabolites in strawberry fruit
}

\author{
Nika Weber ${ }^{1, \star}$, Robert Veberic ${ }^{1}$, Jan Rescic ${ }^{1}$, Maja Mikulic-Petkovsek ${ }^{1}$, Franci Stampar ${ }^{1}$, Darinka Koron ${ }^{2}$ \\ and Alenka Munda ${ }^{2}$ \\ 1 University of Ljubljana, Biotechnical Faculty, Agronomy Department, Chair for Fruit, Viticulture and Vegetable Growing, Jamnikarjeva 101, \\ SI-1000 Ljubljana, Slovenia \\ 2 Agricultural Institute of Slovenia, Hacquetova ulica 17, SI-1000 Ljubljana, Slovenia
}

Received 24 March 2015 - Accepted 21 July 2016

\begin{abstract}
Introduction. Anthracnose disease causes severe economic losses in strawberry (Fragaria $\times$ ananassa) production. Plant response to the pathogen attack is closely linked to its content and composition of polyphenols. In order to reduce the damage caused by pathogens, organic and inorganic fungicides are applied. The aim was to determine the influence of selected fungicides on various metabolites in strawberry fruit. Materials and methods. The efficiency of potassium bicarbonate (PBC) and acetic acid (AA) was compared with the control and a fungicide treatment in the strawberry cv. Elsanta. To examine the possible effects of these fungicides, artificial inoculation was performed in all treatments except for the control. The percentage of infected fruits and the content of selected primary and secondary metabolites in non-infected and infected fruits were determined. Results and discussion. Both analyzed inorganic fungicides proved effective against anthracnose. AA treated fruits were the least infected (only 4\%), followed by $\mathrm{PBC}$, fungicide and control. The highest percentage $(9.26 \%)$ of infected fruits was determined following artificial infection treatment. Total sugar content decreased for $32 \%$ in infected control and AA treated fruits. PBC treatment exhibited a positive effect on the organic acid content in comparison with other treatments. The content of phenolic compounds was higher in PBC treated fruits and did not change significantly after infection. Infection increased the total flavonol content of the fruit. Conclusion. The use of PBC and AA potentially present a prospective protection in the strawberry orchards especially for controlling anthracnose in organic fruit crops.
\end{abstract}

Keywords: strawberry / Fragaria $\times$ ananassa / anthracnose (Colletotrichum spp.) / alternative fungicides / biological control / integrated disease management / phenolics

\begin{abstract}
Résumé - Des produits alternatifs contre l'anthracnose affectent certains métabolites primaires et secondaires de la fraise. Introduction. L'anthracnose provoque des pertes économiques importantes en production de fraises (Fragaria $\times$ ananassa). La réponse de la plante à l'attaque des agents pathogènes est étroitement liée à sa teneur et à sa composition en polyphénols. Pour réduire les dommages causés par les agents pathogènes, des fongicides organiques et inorganiques sont appliqués. Nous avons cherché à déterminer l'influence de ces fongicides sur certains métabolites présents dans la fraise. Matériel et méthodes. L'efficacité du bicarbonate de potassium (PBC) et de l'acide acétique (AA) a été comparée à celle du contrôle et d'un traitement fongicide sur le cultivar Elsanta. En vue d'examiner les effets potentiels de ces fongicides, une inoculation artificielle a été réalisée pour tous les traitements sauf pour le contrôle. Le pourcentage de fruits infectés, ainsi que le contenu en certains métabolites primaires et secondaires contenus dans les fruits non infectés et infectés ont été déterminés. Résultats et discussion. Les deux fongicides inorganiques étudiés se sont révélés efficaces contre l'anthracnose. Les fruits traités à l'AA ont été les moins infectés (seulement $4 \%$ ), suivis par ceux traités au PBC, au fongicide et ceux du contrôle. Le pourcentage le plus élevé $(9,26 \%)$ de fruits infectés a été obtenu suite à une inoculation artificielle. La teneur en sucres totaux a diminué de $32 \%$ dans les fruits du contrôle infecté et ceux traités à l'AA. Le traitement au PBC a montré un effet positif sur la teneur en acides organiques en comparaison avec les autres traitements. La teneur en composés phénoliques a été plus élevée dans les fruits traités au $\mathrm{PBC}$ et n'a pas changé de manière significative après infection. L'infection a augmenté la teneur des fruits en flavonols totaux. Conclusion. L'utilisation du PBC et de l'AA présente une protection potentielle des vergers de fraisiers, en particulier dans la perspective du contrôle de l'anthracnose en culture biologique.
\end{abstract}

Mots clés : fraise / Fragaria $\times$ ananassa / anthracnose (Colletotrichum spp.) / alternative aux fongicides / lutte biologique / gestion intégrée des maladies / composés phénoliques

^ Corresponding author: nika.weber@bf.uni-lj.si 


\section{Introduction}

Colletotrichum, the agent of anthracnose disease, causes severe economic losses in strawberry (Fragaria $\times$ ananassa) production all over the world. The species has been subjected to thorough taxonomic reassessment and is now recognized as a species complex, comprising 31 species. Several species within the $C$. acutatum complex cause strawberry anthracnose; however, Colletotrichum nymphaeae (formerly known as $C$. acutatum molecular group A2 or $C$. simmondsii) is the most harmful [1].

In order to reduce the damage caused by this plant pathogen, several methods have been employed, most commonly chemical control. However, excessive use of fungicides has caused pollution problems and leaves residues in the harvested crops. Strawberry fruit is particularly prone to negative effects of the fungicides, as $C$. nymphaeae usually infects mature fruits. An additional problem is the pathogenic resistance induced by the frequent use of specific fungicides [2]. Their use is also limited due to a lack of pesticides registered for this crop and restrictions imposed on their usage. Different fungicides for anthracnose control have previously been investigated in many research studies, such as treatments with propiconazole [11], benomyl [12] and prochloraz [13]. Garcia de los Santos and Romero [14] published extensive research on the effect of many different fungicides in the control of C. $a c u$ tatum and evaluated their impacts on the disease. Therefore, environmentally friendly control alternatives such as biological control have been sought. The use of antifungal compounds such as bicarbonates [3] and organic acids [4] reportedly reduce the damage caused by $C$. nymphaeae.

Some organic acids have an inhibitory effect on pathogenic organisms. Low $\mathrm{pH}$ levels require high energy inputs of pathogenic organisms to maintain a favorable intracellular $\mathrm{pH}$. The optimal growth of Colletotrichum species has been observed at pH 6.0 and the inhibition of growth by acetic acid has been accelerated and linked with a decrease in $\mathrm{pH}$ from 6.0 to 4.0 [4]. Several researchers thus propose to control $\mathrm{Col}$ letotrichum infection by using acetic acid, which is generally less dangerous than fungicides [4]. Considering the inhibitory role of organic acids, some mechanisms of pathogen repression have been suggested, including membrane disruption with sorbic acid [5] and the interruption of metabolic reactions with benzoate [6].

A different option is to increase $\mathrm{pH}$ level with the use of bicarbonate salts. As reported by Palmer et al. [7], bicarbonate anion appears to be the active portion of the bicarbonate salts even if cations might have some minor effects. Bicarbonates have several modes of action against fungi, including buffering and active increase of the $\mathrm{pH}$ level and the osmotic pressure of cells at the leaf surface. Both factors lead to detrimental conditions for fungal spore growth and germination [7]. The bicarbonate ion has been identified as the probable cause of growth inhibition in some bacteria and fungi. In the case of fungi, hyphal walls collapse in the presence of bicarbonate, causing either growth inhibition or fungal death [8]. It has been reported that potassium bicarbonate inhibited the growth of Trichoderma [9]. High $\mathrm{pH}$ level of leaf and fruit exodermal cells was shown to be effective as a control strategy for apple scab [10].

The most commonly applied products for strawberry anthracnose control are fungicides. However, their use is limited due to a lack of pesticides registered for this crop and restrictions imposed on their usage. Different fungicides for anthracnose control have previously been investigated in many research studies, such as treatments with propiconazole [11], benomyl [12] and prochloraz [13]. De los Santos Garcia de Pareses and Romero Muno [14] published extensive research on the effect of many different fungicides in the control of Colletotrichum acutatum and evaluated their impacts on the disease. Inoculation with $C$. nymphaeae can cause changes in the synthesis of primary and secondary metabolites, as reported in our previous studies [15]. The present study highlights individual phenolic compounds that could be involved in defense mechanisms against specific fungal pathogens. Several research studies indicate that fungicide spraying alters polyphenolic levels in plant cells [16], but other studies [17] suggest that no modification occurs.

Phenolic compounds are toxic to the pathogens, and many of them, such as flavonols and hydroxycinnamic acids, can act as passive or inducible barriers against herbivores or microbes. In response to the pathogen attack, the content and composition of polyphenols can change, playing an active role in induced resistance to the pathogens [18]. Flavonols, epicatechin and anthocyanins have previously been determined in strawberry fruit $[19,20]$ and these compounds presumably inhibit the infection caused by plant pathogens such as Botrytis cinerea.

Therefore, the aim of the study was to examine the effect of Signum fungicide, potassium bicarbonate (PBC) and acetic acid (AA) applications on the polyphenolic composition of strawberry fruit. The specific objectives of the study were: 1) to evaluate the efficiency of inorganic and organic fungicides (PBC and AA), and a commercial fungicide (Signum) in anthracnose control (the percentage of infected fruit); and 2) to assess the influence of these agents on primary and secondary metabolites in strawberry fruit. The working hypothesis is that an application of bicarbonate salt or acetic acid potentially modifies plant secondary metabolism, which in return could induce higher plant resistance to anthracnose.

\section{Materials and methods}

\subsection{Fungal material}

Strawberry fruits with clear symptoms of anthracnose were collected in 2012 at a strawberry plantation near Ljubljana (latitude, $46^{\circ} 03^{\prime} \mathrm{N}$; longitude, $14^{\circ} 30^{\prime} \mathrm{E}$, central Slovenia). Fungal isolates were obtained by culturing fragments of necrotic tissue from rotten strawberry fruit on potato dextrose agar (PDA). They were identified as Colletotrichum nymphaeae (Pass.) on the basis of cultural characteristics and sequence analysis of ITS and TUB2 according to the method of Damm et al. [1]. A single-spore isolate was prepared by spreading spore suspension on PDA plates and isolating individual germinating conidia. Prior to plant inoculation, the single-spore isolate was 
subcultured on PDA plates and incubated at $24{ }^{\circ} \mathrm{C}$ in the dark for 10 days. Spores were then scraped from the plates and dispersed in sterile distilled water. Spore suspension was adjusted to $10^{6}$ spores $\mathrm{mL}^{-1}$.

\subsection{Plant material and growing conditions}

Strawberry frigo plants were planted in July 2012 on an open field and the trial was conducted in spring 2013 at the experimental station of the Agricultural Institute of Slovenia, located at Brdo pri Lukovici (latitude, $46^{\circ} 10^{\prime} \mathrm{N}$; longitude, $12^{\circ} 41^{\prime}$ E). The experiment was set under controlled conditions in a greenhouse in order to eliminate the influence of the environment (rain-water supply, temperature, humidity...) and ensure equal growing conditions. The soil texture was silty loam, rich in potassium and nitrogen and poor in phosphorus. The organic matter was high. Plants of cv. Elsanta were planted on slightly elevated beds covered with black polyethylene at a spacing of $0.25 \mathrm{~m} \times 0.25 \mathrm{~m}$ in double rows.

The experimental site was equipped with a drip irrigation system. Six blocks with four treatments were established; each treatment per block included 10 plants: (1) artificial inoculation with $C$. nymphaeae; (2) artificial inoculation with C. nymphaeae and spray application of pyraclostrobin + boscalid (fungicide Signum, BASF); (3) artificial inoculation with $C$. nymphaeae and foliar spraying with potassium bicarbonate (Vitisan, BIOFA); (4) artificial inoculation with $C$. nymphaeae and spraying application of $1 \%$ acetic acid and (5) control (spraying with water). Plants were first sprayed with Signum on May $22^{\text {nd }}$, and with Vitisan and acetic acid on May $22^{\text {nd }}, 29^{\text {th }}$ and June $3^{\text {rd }}$. The control treatment plants were sprayed with water on the same dates. After spraying according to specific treatments, spore suspension (May $22^{\text {nd }}$ ) was applied to the plants by spraying till runoff with a hand sprayer. Immediately after inoculation (in the afternoon), plants were covered with a transparent polyethylene cover, to maintain $100 \%$ relative humidity and were kept covered overnight. The cover was removed in the morning to avoid high temperatures at daytime. The first strawberries were harvested five days after sprayings when the fruits turned bright red (on May $27^{\text {th }}$ ) and were harvested two to three times per week for the period of three weeks. On each harvest fruit yield and number of infected fruits per plant were assessed. Fruits for further analysis were immediately frozen in liquid nitrogen and stored for up to 1 month at $-20{ }^{\circ} \mathrm{C}$ until chemically analyzed. The infection was evaluated based on visible symptoms as infected fruit surfaces were covered with black necrotic lesions, which are typical symptoms for infection with $\mathrm{Col}$ letotrichum species.

\subsection{Chemicals}

The following standards were used for the determination of sugars and organic acids: sucrose, fructose, and glucose and citric, malic, and fumaric acid from Fluka Chemie (Buchs, Switzerland); shikimic acid from Sigma-Aldrich (Steinheim, Germany). For the quantitation of phenolic compounds the following standards were used: ellagic acid, cyanidin-3glucoside, and pelargonidin-3-glucoside from Sigma-Aldrich Chemicals (St. Louis, MO, USA); quercetin-3galactoside, quercetin-3-glucoside, quercetin-3-glucuronide, kaempferol3-glucoside, (-)-epicatechin, $p$-coumaric acid, and procyanidin B2 from Fluka Chemie. Methanol for the extraction of phenolics was acquired from Sigma-Aldrich Chemicals. The chemicals for the mobile phases were HPLC-MS grade acetonitrile and formic acid from Fluka Chemie GmBH. Water for the mobile phase was double-distilled and purified with a Milli-Q system (Millipore, Bedford, MA, USA).

\subsection{Extraction and determination of sugars and organic acids}

Primary metabolites (sugars and organic acids) were analyzed in whole strawberry fruit. For each treatment, six repetitions were carried out $(n=6)$; each repetition included several fruits. For the extraction of primary metabolites, $5 \mathrm{~g}$ fruit was homogenized in $25 \mathrm{~mL}$ of double-distilled water using an Ultra-Turrax T-25 (Ika-Labortechnik) and left for $30 \mathrm{~min}$ at room temperature as reported by Mikulic-Petkovsek et al. [21]. After the extraction, the homogenate was centrifuged (Eppendorf Centrifuge $5810 \mathrm{R}$ ) at $12,000 \mathrm{rpm}$ for $7 \mathrm{~min}$ at $10{ }^{\circ} \mathrm{C}$. The supernatant was filtered through a $0.20 \mu \mathrm{m}$ cellulose ester filter (Macherey-Nagel) and transferred into a vial, and $20 \mu \mathrm{L}$ of the sample was used for the analysis. The analysis of primary metabolites was carried out using a high-performance liquid chromatograph (HPLC) of Thermo Separation Products (San Jose, CA, USA). The separation of sugars was carried out using a $300 \mathrm{~mm} \times 7.8 \mathrm{~mm}$ i.d. Rezex RCM monosaccharide $\mathrm{Ca}+2 \%$ column from Phenomenex operating at $65^{\circ} \mathrm{C}$. The mobile phase was double-distilled water, and the flow rate was $0.6 \mathrm{~mL} \mathrm{~min} \mathrm{~min}^{-1}$; the total run time was $30 \mathrm{~min}$, and a refractive index (RI) detector was used to monitor the eluted carbohydrates as described by Mikulic-Petkovsek et al. [21]. Organic acids were analyzed with the same HPLC system, equipped with a UV detector set at $210 \mathrm{~nm}$, using a $300 \mathrm{~mm} \times$ $7.8 \mathrm{~mm}$ i.d. Rezex ROA-organic acid $\mathrm{H}+(8 \%)$ column from Phenomenex, as described by Mikulic-Petkovsek et al. [21]. The column temperature was set at $65^{\circ} \mathrm{C}$. The elution solvent was $4 \mathrm{mM}$ sulfuric acid in double-distilled water at a flow rate of $0.6 \mathrm{~mL} \mathrm{~min}{ }^{-1}$. The duration of the analysis was $30 \mathrm{~min}$. The sugars and organic acids in strawberry extracts were identified by their retention time characteristics and compared with standards; their content was calculated with the help of the corresponding external standard and expressed as $\mathrm{g} \mathrm{kg}^{-1}$ fresh weight (FW) for sugars and $\mathrm{g} \mathrm{kg}^{-1}$ or $\mathrm{mg} \mathrm{kg}^{-1} \mathrm{FW}$ for organic acids. The content of all analyzed sugars was summed up and presented as total analyzed sugars. In a similar way total analyzed organic acids were calculated.

\subsection{Extraction of phenolic compounds}

The extraction of fruit samples was performed as described by Mikulic-Petkovsek et al. [21] with some modification. Phenolic compounds (flavonoids and phenolic acids) 
were analyzed in whole strawberry fruit. For each treatment, six repetitions were carried out $(n=6)$; each repetition included several fruits. Frozen fruits were ground to a fine pulp in a mortar chilled with liquid nitrogen, and $5 \mathrm{~g}$ was extracted with $10 \mathrm{~mL}$ of methanol containing $3 \%(\mathrm{v} / \mathrm{v})$ formic acid and 1\% (w/v) 2,6-di-tert-butyl-4methylphenol (BHT) in a cooled ultrasonic bath for $1 \mathrm{~h}$. BHT was added to the samples to prevent oxidation. After extraction, the fruit extracts were centrifuged for $10 \mathrm{~min}$ at $10000 \mathrm{rpm}$. Each supernatant was filtered through a Chromafil AO20/25 polyamide filter produced by Macherey-Nagel (Duren, Germany) and transferred to a vial prior to injection into the high performance liquid chromatography (HPLC) system.

\subsection{Determination of individual phenolic compounds using HPLC-DAD-ESI/MS ${ }^{\mathrm{n}}$ analysis}

Phenolic compounds were analyzed on a Thermo Finnigan Surveyor HPLC system (Thermo Scientific) with a diode array detector at $280 \mathrm{~nm}$ (flavanols, hydroxycinnamic acid derivatives), $350 \mathrm{~nm}$ (flavonols) and $530 \mathrm{~nm}$ (anthocyanins). Spectra of the compounds were recorded between 200 and $600 \mathrm{~nm}$. The column was a $150 \times 4.6 \mathrm{~mm}$ internal diameter, $3 \mu \mathrm{m}$, Gemini C18 (Phenomenex, Torrance, CA, USA) operated at $25{ }^{\circ} \mathrm{C}$. The elution solvents were aqueous $0.1 \%$ formic acid in double-distilled water (A) and $0.1 \%$ formic acid in acetonitrile (B). Samples were eluted according to the linear gradient from 5 to $20 \%$ B in the first 15 min, followed by a linear gradient from 20 to $30 \%$ B for $5 \mathrm{~min}$, then an isocratic mixture for $5 \mathrm{~min}$, followed by a linear gradient from 30 to $90 \% \mathrm{~B}$ for $5 \mathrm{~min}$, and then an isocratic mixture for $15 \mathrm{~min}$ before returning to the initial conditions. The injection amount

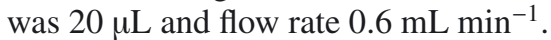

All phenolic compounds were identified using a mass spectrometer (Thermo Scientific, LCQ Deca XP MAX) with electrospray ionization (ESI) operating in negative ion mode (all phenolic groups except for anthocyanins) and positive ion mode (anthocyanins). The analyses were carried out using full scan data-dependent $\mathrm{MS}^{\mathrm{n}}$ scanning from $\mathrm{m} / \mathrm{z} 115$ to 1500 . The injection volume was $10 \mu \mathrm{L}$, and the flow rate was maintained at $0.6 \mathrm{~mL} \mathrm{~min}^{-1}$. The capillary temperature was $250{ }^{\circ} \mathrm{C}$, the sheath gas and auxiliary gas were 20 and 8 units, respectively, and the source voltage was $4 \mathrm{kV}$ for negative ionization and $0.1 \mathrm{kV}$ for positive ionization. Spectrometric data were elaborated using the Excalibur software (Thermo Scientific). The identification of compounds was confirmed by comparing retention times and their spectra as well as by adding the standard solution to the sample and by fragmentation. The content of phenolic compounds was calculated from peak areas of the sample and the corresponding standards and expressed in $\mathrm{mg} \mathrm{kg}^{-1} \mathrm{FW}$ strawberry fruit. For compounds lacking standards, quantitation was carried out using similar compounds as standards. Thus, glycosides of kaempferol were quantitated in equivalents of kaempferol-3-glucoside, all procyanidin dimers and trimers in equivalents of procyanidin $\mathrm{B} 2 ; p$ coumaric acid derivatives was quantitated in equivalents of $p$-coumaric acid, pelargonidin-3-malonylglucoside in equivalents of pelargonidin-3-glucoside and all ellagic acid derivatives were quantitated in equivalents of ellagic acid.
Table I. The effect of different treatments on strawberry fruit infection $(\%)$.

\begin{tabular}{ll}
\hline Treatment & \% of infected fruits \\
\hline PBC & $7.47 \pm 0.75 \mathrm{ab}$ \\
AA & $4.07 \pm 0.61 \mathrm{a}$ \\
Fungicide & $7.23 \pm 0.84 \mathrm{ab}$ \\
Artificial infection & $9.26 \pm 0.76 \mathrm{~b}$ \\
Control & $7.20 \pm 0.61 \mathrm{ab}$ \\
\hline
\end{tabular}

Different letters in columns denote statistically significant differences among treatments by Duncan's test at $P<0.05$.

\subsection{Statistical analysis}

The data were analyzed using the Statgraphics Plus 4.0 program (Manugistics, Inc., Rockville, MD, USA). A twoway analysis of variance was carried out to determine the significance of infection and treatment (control, PBC, AA, fungicide, and artificial inoculation treatment) on strawberry fruit phenolic profile. The significance of the treatment on individual phenolic compound, sugar and organic acid contents was tested using one-way analysis of variance (ANOVA). Diferences among treatments were tested with Duncan's test at a $P<0.05$ significance level.

\section{Results and discussion}

The first symptoms of $C$. nymphaeae infection appeared during fruit maturation. The percentage of infected fruits at different treatments is presented in table I. The highest number of infected fruits was recorded following artificial infection $(9.26 \%)$ and statistically lowest in acetic acid treated plants (4.07\%). This indicates that acetic acid successfully inhibited the infection on strawberry fruit. It has been reported that organic acids and their salts alone on or in combination inhibit the growth of bacteria and fungi [4].

\subsection{The content of sugars and organic acids in strawberry fruit}

Three main sugars (fructose, glucose and sucrose) were quantified in non-infected and infected strawberry fruits. Fructose and glucose were quantitatively the most important ( $t a-$ ble II) and the latter was generally measured in highest levels (from 19.22 in infected control fruits to $25.28 \mathrm{~g} \mathrm{~kg}^{-1} \mathrm{FW}$ in artificially inoculated infected fruits). Glucose levels also varied among treatments; 11.78 were measured in infected control fruits and $23.41 \mathrm{~g} \mathrm{~kg}^{-1} \mathrm{FW}$ in fungicide treated infected fruits. The content of sucrose was much lower (from 0.67 in acetic acid treated infected fruits to $5.11 \mathrm{~g} \mathrm{~kg}^{-1} \mathrm{FW}$ in non-infected control). Mikulic-Petkovsek et al. [21] reported similar results for two different strawberry cultivars. Treatment $(P=0.009)$ and infection $(P=0.000)$ significantly affected the content of total sugars. Lowest levels of total sugars have been determined in infected fruits of the control and AA treatment. Control plants were only sprayed with water and the infection occurred without artificial inoculation resulting in low total sugar 


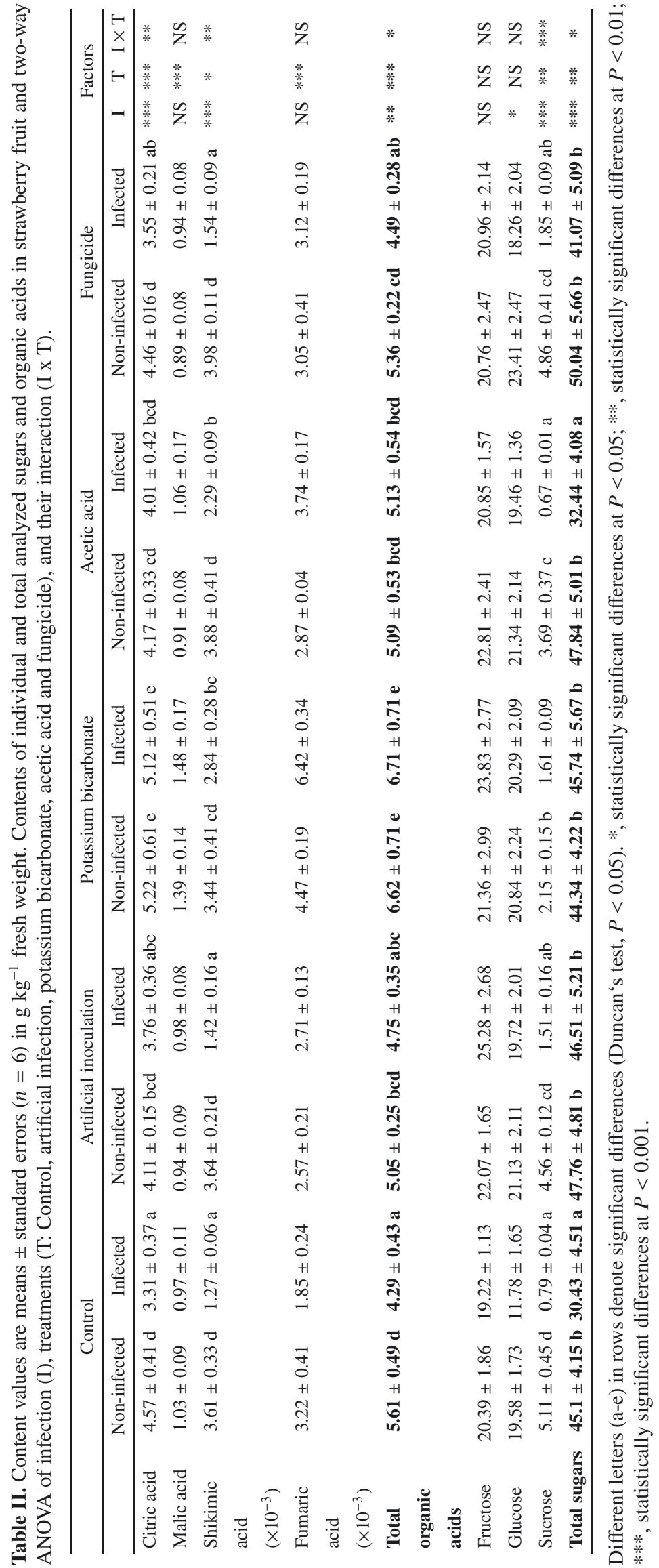


levels. Contrary to the expected results, acetic acid application did not diminish the onset of artificial inoculation in terms of sugar accumulation.

The main organic acids determined in strawberry fruit were citric and malic acid. This is in accordance with previous results $[15,21]$. The combined share of citric and malic acids in strawberries represented almost $99 \%$ total organic acids ( $t a$ ble $I I I)$. Similar to sugars, treatment $(P=0.000)$ and infection $(P=0.003)$ affected the content of total organic acids. Fruits treated with $\mathrm{PBC}$ contained significantly higher amounts of total organic acids compared to other treatments. Infection with anthracnose caused a decrease in total organic acid content in all treatments except for PBC and AA treated plants. These could be linked to the fact that fungus infection increases the $\mathrm{pH}$ level of fruit, and PBC (Vitisan, $\mathrm{pH}=8$ ) acts as an alkali medium. Ortega-Aguilar et al. [9] reported that potassium bicarbonate gradually increased $\mathrm{pH}$ level of the culture media from 6.5 (control) to 8.0 and $\mathrm{KHCO}_{3}$ significantly inhibited fungal growth after $24 \mathrm{~h}$. A significant decrease of total organic acids was detected in infected control and fungicide treated fruits (17 and $24 \%$, respectively) compared to non-infected fruits of the same treatments. Our previous research [15] demonstrated that the content of organic acids is lower in Colletotrichum simmondsii infected strawberry fruits. Pathogenic fungi namely utilize carbon from organic acids for their growth and development [22] and at the same time secrete cell wall degrading enzymes [23].

\subsection{Phenolic content in strawberry fruit}

Strawberry phenolic profile varies significantly among cultivars [19]. The 'Elsanta' cultivar was used in the present study as it represents one of the most commonly planted cultivars in European strawberry production. In infected and non-infected strawberry fruits, 34 different phenolic compounds have been determined and grouped into the following phenolic classes: ellagic acid derivatives, hydroxycinnamic acids derivatives, anthocyanins, flavonols and flavanols (table III). The greatest share of all identified phenolic compounds (AIP) in strawberry fruit was presented by flavanols (64\% AIP), and anthocyanins (25\% AIP).

Ellagic acid (EA) occurs in different forms: as free EA, glycosylated via its hydroxyl groups or, more commonly, as complex polymers esterified with a sugar known as ellagitannins (ETs) [24]. Nine (9) different forms of ellagic acid have been identified in strawberry fruit. The content of ellagic acid derivatives increased for $44 \%$ at $\mathrm{PBC}$ and for $27 \%$ at AA treatment in comparison with the control (table III). A significant increase of EA forms has been determined at PBC treatment compared to the fungicide, artificial infection and control treatment. This suggests that PBC boosts the formation of ellagic acid derivatives, which are known to possess antimicrobial activity [25]. Bicarbonate salts similarly provide broad-spectrum antimicrobial activity [26]. Plants often increase the accumulation of specific compounds, such as ellagic acid and its derivatives, to better resist various stress condition.

Flavonols represented approximately 2\% AIP in strawberry fruit, which is in agreement with other studies [21]. Although flavonols are not essential for the survival of plants they are important phenolic compounds as they enhance the plant's ability to withstand stress factors such as pathogens [27]. Control fruits contained significantly lower levels of total flavonols in comparison with other treatments, except for fungicide treatment $(P=0.02)$ (table $I I I)$. Specifically, PBC (1.8 fold) and AA (1.7 fold) treatments increased total flavonol content compared to control fruits. All treatments clearly stimulated flavonol formation, especially in non-infected fruits. Individual flavonols were similarly affected by the Colletotrichum infection and infected strawberries contained significantly higher levels of kaempferol-3-glucoside (up to 36\%) in all treatments except at PBC. Infection did not cause significant changes in the latter. A significant decrease of quercetin-3glucuronide levels has also been measured in PBC (a 58\% decrease) and AA (a 54\% decrease) treated infected fruits. It has been reported that quercetin is an antimicrobial compound synthesized by plants in response to pathogen attack [28]. Similar to these findings, higher content levels of several flavonols have been recorded in fruit infected with various pathogens, bacteria, or viruses compared to non-infected tissue [29].

Catechin and procyanidin trimer 5 were the most abundant flavanols in strawberry fruit and combined represented $40-46 \%$ total analyzed flavanols (table III). Infected strawberry fruit contained significantly higher levels of total flavanols compared to non-infected fruit of the corresponding treatment. The infection caused from 1.1 to 1.3 fold increase of total flavanols. Specifically, procyanidin tetramer 1 and 3 (1.1 to 3.2 fold) and procyanidin trimer 2 and 3 (1.5 to 2.2 fold) increased significantly with the Colletotrichum infection. On the contrary, the level of procyanidin tetramer 2 decreased in infected fruit regardless of the treatment. Several researchers $[15,21]$ have also observed a dramatic increase in monomeric flavanols and their polymers in the infected tissue. The role of flavanols in mechanisms of pathogen defense might be their interaction with proteins and the inhibition of enzyme activity secreted by the pathogenic fungi [18].

Treatments and infection modified hydroxycinnamic acid content $(P=0.000)$. Strawberries under fungicide treatment contained significantly lower levels of total hydroxycinnamic acids compared to AA treated fruits. Infection caused a significant increase of hydroxycinnamic acids in control strawberries. An analogous response has been reported in apple tissue infected with $V$. inaequalis fungus [30] as a result of stress. C. nymphaeae infection significantly increased the content of sinapoyl hexoside (1.0 to 1.5 fold), the major hydroxycinnamic acid identified in strawberry fruit (table III). It has previously been determined that hydroxycinnamic acid derivatives play a major role in plant resistance and exhibit a fungi toxic effect against different pathogens inhibiting the growth and sporulation of fungi [31]. The content of additional hydroxycinnamic acid derivatives changed as a result of different treatments. AA caused an increase of $p$-coumaric acid hexoside 1 for more than 2.3 fold in non-infected fruits in comparison to the control treatment.

The major anthocyanin identified in strawberry fruit was pelargonidin-3-glucoside, which represented 69-82\% total analyzed anthocyanins (table III). The content of anthocyanins is greatly influenced by fruit maturity level and cultivar [21] but in the present study only one cultivar has been analyzed and 

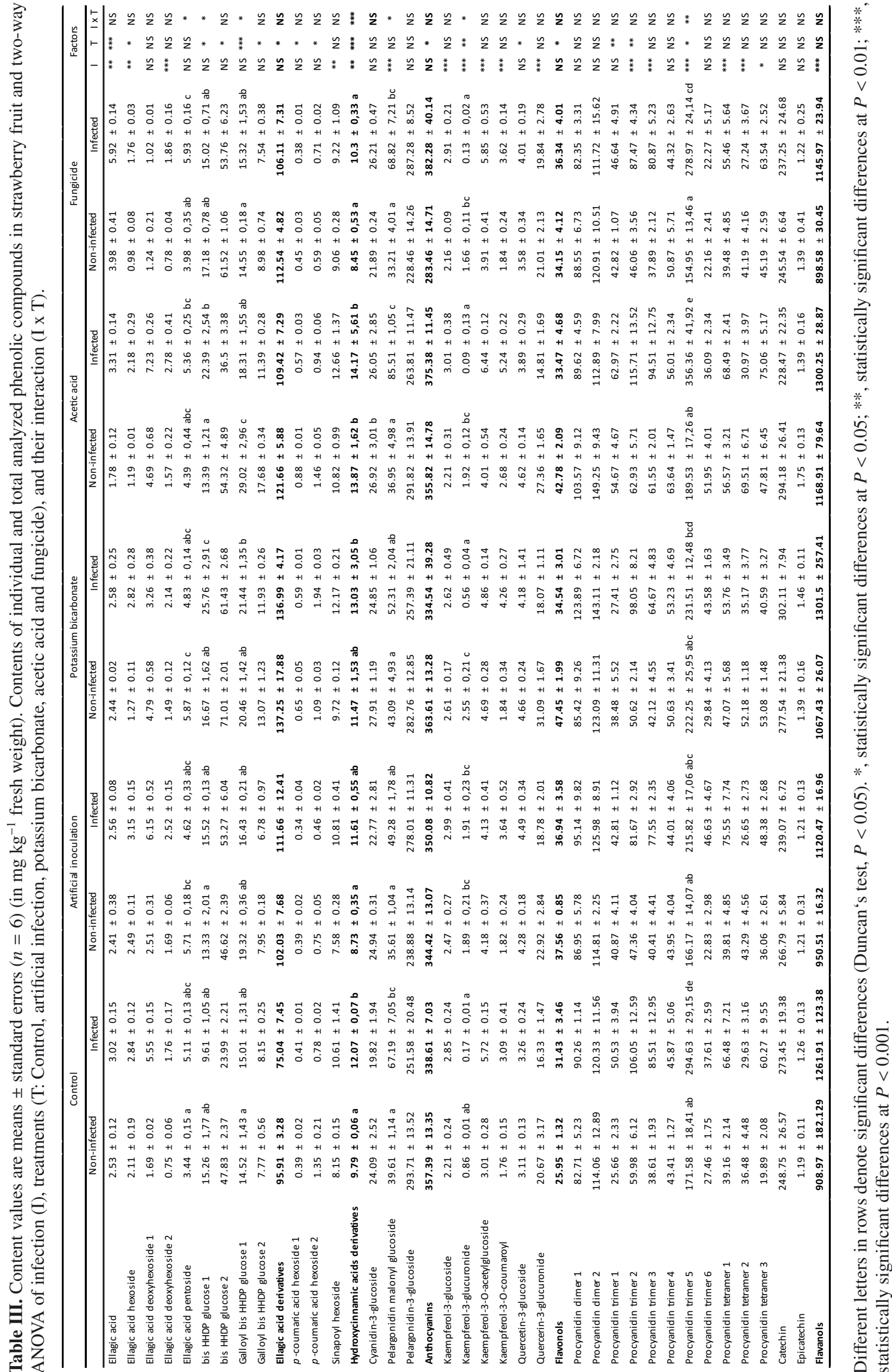
fruits were at the same ripening stage. Statistically the lowest content of total analyzed anthocyanins has been measured in the fungicide treatment compared to other treatments. Slatnar et al. [10] also observed an increase of anthocyanins in PBC treated apple fruit compared to the fungicide treatment used against apple scab. Hunsche et al. [32] observed that fruit color was positively correlated with the amount of potassium applied to the soil and also with the fruit anthocyanin content, inferring that potassium might be important in the anthocyanin synthesis pathway. Only pelargonidin malonyl glucoside content significantly increased after infection. In the control treatment, the level of this anthocyanin increased 1.7 fold and a more than 2.1 and 2.3 fold increase has been measured at fungicide and AA treatments, respectively. This is in accordance with the reports of Mikulic-Petkovsek et al. [21]. Interestingly, at PBC treatment the content of malonyl glucoside only increased approximately 1.2 fold.

\section{Conclusion}

Strawberry anthracnose is a severe disease in commercial strawberry production all over the world. In years with abundant rainfall a large number of fungicide treatments are required during the ripening season. This potentially leads to the accumulation of toxic chemical residues in strawberry fruit. Therefore, it is necessary to use alternative non-toxic products such as potassium bicarbonate and acetic acid. The study points out the potential relevance of bicarbonate salts and acetic acid for controlling $C$. nymphaeae and includes the following findings: a) the use of acetic acid (AA) led to a lower percentage of infected strawberry fruits; b) treatments and $C$. nymphaeae infection modified sugars and organic acids accumulation. Infection caused a decrease of total sugars in control and AA treated plants. Fruits treated with potassium biocarbonate (PBC) contained significantly higher amounts of total organic acids compared to other treatments. Infection with anthracnose caused a decrease in total organic acids content in all treatments except for PBC and AA treated plants; c) contents of total flavonols and total ellagic acid derivatives were higher with $\mathrm{PBC}$ or AA treatments compared to the control; d) infected strawberry fruit contained significantly higher levels of flavanols. The advantage of PBC or AA application is that these products do not accumulate in the soil and are non-toxic to human health. These alternative protective products should be investigated in detail and tested for practical use in organic strawberry production.

\section{References}

[1] Damm U., Cannon P.F., Woudenberg J.H.C., Crous P.W., The Colletotrichum acutatum species complex, Stud. Mycol. (2012) 37-113.

[2] Van Dyk J.S., Pletschke B., Review on the enzymes for the detection of organochlorine, organophosphate and carbamate pesticides in the environment, Chemosphere 83 (2011) 291-307.
[3] Ibra-Medina V.A., Ferrera-Carrato R., Alarcon A., LaraHernandez M.E., Valdez-Cerrasco J.M., Isolation and screening of Trichoderma strains antagonistic to Sclerotinia sclerotiorum (Lib) de Bary and Sclerotinia minor Jagger. Revista Mexicana de Micologia, 31 (2010) 53-63.

[4] Kang H., Park Y., Go S., Growth inhibition of a phytopathogenic fungus, Colletotrichum species by acetic acid, Microbiol. Res. 158 (2003) 321-326.

[5] Bracey D., Holyoak C.D., Coote P.J., Comparison of the inhibitory effect of sorbic acid and amphotericin B on Saccharomyces cerevisiae: is growth inhibition depended on reduce intracellular pH? J. Appl. Microbiol. 85 (1998) 1056-1066.

[6] Krebs H.A., Wiggins D., Sole S., Bedoya F., Studies on the mechanism of the antifungal action of benzoate, Biochem. J. 214 (1983) 657-663.

[7] Palmer C.L., Horst R.K., Langhans R.W., Use of bicarbonate to inhibit in vitro colony growth of Botrytis cinerea. Plant Dis. 81 (1997) 1432-1438.

[8] Ordonez-Valencia C., Alarcon A., Ferrera-Cerrato R., Hernandez-Cuevas L.V., In vitro antifungal effects of potassium bicarbonate on Trichoderma sp and Sclerotinia sclerotiorum, Mycoscience 50 (2009) 380-387.

[9] Ortega-Aguilar B.L., Alarcon A., Cerrato-Ferreta R., Effect of potassium bicarbonate on fungal growth and sclerotia of Sclerotium cepivorum and its interaction with Trichoderma, Revista Mexicana de Micologia 33 (2011) 53-61.

[10] Slatnar A., Stampar F., Veberic R., Influence of bicarbonate salts, used against apple scab, on selected primary and secondary metabolites in apple fruit and leaves, Sci. Hortic. 143 (2012) 197-204.

[11] Smith B.J., Black L.L., Greenhouse efficacy of fungicides for control of anthracnose crown rot of strawberry, in: Adam, D., James, J.L. (Eds.), The Strawberry into the $21^{\text {st }}$ Century, Timber Press, Portland, OR, 1991, pp. 221-226.

[12] Gubler W.D., Gunnell P.S., Welch N.C., Buchner R., Strawberry diseases and control, Annual report of strawberry research california strawberry advisory Board, 1988, pp. 12-36.

[13] Freeman S., Nizani Y., Dotan S., Even S., Sando T., Control of Colletotrichum acutatum in strawberry under laboratory, greenhouse and field conditions, Plant Dis. 81 (1997) 749-752.

[14] De los Santos G. de P.B., Romero M.f., Occurrence of Colletotrichum acutatum, causal organism of strawberry anthracnose in southwestern Spain. Plant Dis. 83 (1999) 301.

[15] Weber N., Schmitzer V., Jakopic J., Mikulic-Petkovsek M., Stampar F., Koron D., Veberic R., Influence of Colletotrichum simmondsii R.G. Shives Y.P. Tan infection on selected primary and secondary metabolites in strawberry (Fragaria $\times$ ananassa Duch.) fruit and runners, Europ. J. Plant Pathol. 136 (2013) 281-290.

[16] Ruiz J.M., Garcia P.C., Rivero R.M., Romero L., Response of phenolic metabolism to the application of carbendazim plus boron in tobacco, Physiol. Plant. 106 (1999) 151-157.

[17] Osbourn A.E., Preformed antimicrobial compounds and plant defense against fungal attack, Plant Cell 8 (1996) 1821-1831.

[18] Treutter D., Feucht W., Accumulation of plavan-3-ols in fungus infected leaves of Rosaceae, Z. Pflanzenk. Pflanzen. 97 (1990) 634-641. 
[19] Aaby K., Mazur, S., Nes, A., Skrede, G., Phenolic compounds in strawberry (Fragaria $\times$ ananassa Duch.) fruits: composition in 27 cultivars and changes during ripening, Food Chem. 132 (2012) 86-97.

[20] Kajdžanoska M., Petreska J., Stefova M., Comparison of different extraction solvent mixtures for characterization of phenolic compounds in strawberries, J. Agric. Food Chem. 59 (2011) 5272-5278.

[21] Mikulic-Petkovsek M., Schmitzer V., Slatnar A., Veberic R., Munda A., Koron D., Stampar F., Alteration of the content of primary and secondary metabolites in strawberry fruit by Colletotrichum nymphaeae infection, J. Agric. Food Chem. 61 (2013) 5987-5995.

[22] Kamilova F., Kravchenko L.V., Shaposhnikov A.I., Makarova N., Lugtenberg, B., Effects of the tomato pathogen Fusarium oxysporum f. sp radicis-lycopersici and of the biocontrol bacterium Pseudomonas fluorescens WCS365 on the composition of organic acids and sugars in tomato root exudate, Mol. PlantMicrobe Interact. 19 (2006) 1121-1126.

[23] Prusky D., McEvoy J.L., Leverentz B., Conway W.S., Local modulation of host $\mathrm{pH}$ by Colletotrichum species as a mechanism to increase virulence, Mol. Plant-Microbe Interact. 14 (2001) 1105-1113.

[24] Clifford M.N., Scalbert A., Ellagitannins - nature, occurrence and dietary burden, J. Sci. Food Agric. 80 (2000) 1118-1125.

[25] Zhou L.G., Li D., Jiang W.B., Qin Z.Z., Zhao S., Qiu M.H., Wu J.Y. Two ellagic acid glycosides from Gleditsia sinensis Lam.
With antifungal activity on Magnaporthe grisea, Nat. Prod. Res. 21 (2007) 303-309.

[26] Fallik E., Grinberg S., Ziv O., Potassium bicarbonate reduces postharvest decay development on bell papper fruits, J. Hort. Sci. Biotechnol. 72 (1997) 35-41.

[27] Robards K., Prenzler P.D., Trucker G., Swatsitang P., Glover $\mathrm{W}$., Phenolic compounds and their role in oxidative processes in fruits, Food Chem. 66 (1999) 401-436.

[28] Dixon R.A., Paiva N.L., Stress-induced phenylpropanoid metabolism, Plant Cell 7 (1995) 1085-1097.

[29] Rusjan D., Halbwirth H., Stich K., Mikulic-Petkovsek M., Veberic R., Biochemical response of grapevine variety 'Chardonay' (Vitis vinifera L.) to infection with grapevine yellows (Bois noir). Eur. J. Plant Pathol. 134 (2012) 231-237.

[30] Mikulic-Petkovsek M., Stampar F., Veberic R., Accumulation of phenolic compounds in apple in response to infection by the scab pathogen, Venturia inaequalis, Physiol. Mol. Plant Pathol. 74 (2009) 60-67.

[31] Sammi S., Masud T., Effect of different packaging system on the quality of tomato (Lycopersicum esculentum var. 'Rio Grande') fruits during storage, Int. J. Food Sci. Technol. 44 (2009) 918-926.

[32] Hunsche M., Brackmann A., Ernani P.R., Effect of potassium fertilization on the postharvest quality of 'Fuji' apples, Pesqui. Agropecu. Bras. 38 (2003) 489-496. 